\title{
$\mathbb{A}$ Economics Bulletin
}

\author{
Volume 33, Issue 3
}

\section{Inventory Investment Dynamics and Recoveries: A Comparison of Manufacturing and Retail Trade Sectors}

\author{
Frederique Bec \\ Cergy-Pontoise University, THEMA, CREST-ENSAE, \\ Banque de France
}

\author{
Marie Bessec \\ Banque de France, DGEI-DCPM-DIACONJ, Paris- \\ Dauphine University, LEDa-CGEMP
}

\begin{abstract}
This paper explores the existence of a bounce-back effect in inventory investment using the European Commission opinion survey on stocks of finished products in manufacturing and retail trade sectors for France, Germany and a European aggregate, from 1985q1 to 2011 q4. Our empirical findings support the existence of a high recovery episode for inventory investment, during the quarters immediately following the recessions: it occurs later and lasts longer in manufacturing than in retail trade sector. Since a third phase of rapid recovery has not been found in final sales data so far, the rebound in inventories could in turn explain the GDP growth bounce-back pointed out in previous empirical studies. This calls for a careful modeling of the inventory investment behavior in any sensible theoretical explanation of aggregate business cycles.
\end{abstract}

\footnotetext{
We are grateful to L. Wenzel and the participants of the CIRET conference in Vienna, M. Ben Salem, O. Bouabdallah, S. Haincourt, B. Pluyaud, P. Sicsic and an anonymous referee for their comments and suggestions. This paper reflects the opinions of the authors and does not necessarily express the views of the Banque de France.

Citation: Frederique Bec and Marie Bessec, (2013) "Inventory Investment Dynamics and Recoveries: A Comparison of Manufacturing and Retail Trade Sectors", Economics Bulletin, Vol. 33 No. 3 pp. 2209-2222.

Contact: Frederique Bec - bec@ensae.fr, Marie Bessec - marie.bessec@dauphine.fr.

Submitted: July 03, 2012. Published: September 03, 2013.
} 


\section{Introduction}

Since Abramovitz (1950), the role of inventory investment in business cycles is considered as important, even though often neglected. This belief basically stems from the stylized facts that inventory investment is procyclical and in general slightly positively correlated with sales, while the variance of production is greater than the variance of sales. ${ }^{1}$ Hence, as production is the sum of final sales and inventory investment from a national accounting perspective, the latter is suspected to exacerbate business cycles.

Yet, a growing number of empirical studies find evidence of a high-growth recovery phase following contractions in real GDP growth rate data (see e.g. Sichel 1994, Kim and Nelson 1999, Kim et al. 2005, Bec et al. 2011, Morley and Piger 2012 or Bec et al. 2013). In the early sixties, this feature was pointed out by Milton Friedman — see Friedman (1993). Underlying the "plucking" model he then proposed is the idea of the path of a string attached to the underside of a board which is plucked downward: the board underside corresponds to the maximum feasible, or natural level of, output. No matter the extent of the decline, the output will always rebound to the ceiling level. To our knowledge, the origins of this bounce-back phenomenon have hardly been explored so far. The theoretical literature on inventory investment basically considers four motives for holding inventories. The production smoothing motive — see e.g. Blinder (1986) for a comprehensive presentation — was the most popular one until the eighties. Probably due to its counter-factual prediction regarding the relative volatility of output and final sales, alternative motives have been put forward since then: $i)$ the reduction of fixed order costs which grounds the so-called $(S, s)$ rule was first promoted by Blinder (1981), ii) the avoidance of stockouts is the motive proposed by Kahn (1987) while iii) the production-costs smoothing motive is analyzed in a partial equilibrium model by Eichenbaum (1989). Nevertheless, even though a motive may bunch production by producing more than sales at the firm level - for instance to smooth a transitory favorable cost shock or when the floor of minimum stocks, $s$, is reached - its impact on aggregate output is not trivial. Within a dynamic stochastic general equilibrium setup, recent works by Wang and Wen (2009) and Wang et al. (2011) suggest that the production-cost smoothing motive or a firm-level $(S, s)$ policy for holding inventories respectively may explain a bounceback effect in the aggregate output as long as there is one in the inventory investment. This motivates the empirical investigation of inventory investment dynamics proposed in this paper.

Indirect empirical evidence for the inventory investment bounce-back effect is provided in Sichel (1994) from US data. Basically, since the real output is the sum of the final sales and the inventory investment, this author tests for a bounce-back effect in final sales using a very simple regression allowing the average growth rate of the final sales to switch across expansion/contraction/recovery phases over the business cycle. As the lack of bounce-back effect null hypothesis is not rejected for the final sales, whereas it is for the real GDP growth rate, Sichel (1994) concludes that the latter originates in the inventories bounceback. A direct test by Camacho et al. (2011) using more recent US data on inventory investment contribution to GDP growth confirms Sichel's conclusion. More recently, Bec and

\footnotetext{
${ }^{1}$ See Blinder and Maccini (1991) for a detailed discussion of these stylized facts and the competing economic theories as of the end of the eighties.
} 
Ben Salem (2013) have used French national account data to test for the presence of a bounceback effect in inventory investment contribution to real GDP growth rate. More precisely, they retain the bounce-back augmented threshold autoregressive model proposed recently by Bec et al. (2013) to account for periods of high-growth recoveries following the cycle trough $^{2}$. Their first results are quite encouraging, but still open to criticism due to the very nature of the data. Actually, inventory investment data are measured by the French national statistics Institute (INSEE) as the difference between the national sources and uses other than inventories, namely intermediate consumption, final consumption, gross fixed capital formation and exports. If the latter were perfectly measured, then so would the inventory investment data. In general, any measurement error in the various uses will contaminate the measure of inventory investment. As a consequence, these inventory investment data are also subject to large revisions.

Our contribution to this literature is twofold. First, we circumvent this data issue by using European opinion survey data instead. Survey data gives a qualitative but direct assessment by the firm leaders on the level of inventories and is not subject to revision (but for the last available observation so as to include the latest answers). Second, the use of survey data gives us the opportunity to distinguish the inventory investment in finished goods by industrial firms and the one by retail traders ${ }^{3}$. This is not possible with the quarterly accounts where only a decomposition by products is available. This is interesting since the inventory behavior is likely to depend on the position of the firm in the production process, as emphasized in e.g. Blinder and Maccini (1991) and Rougemont (2011). For instance, inventories of finished goods are expected to adjust quicker to the desired level in retail trade than in manufacturing. Inventory investment is also found to be less volatile in the latter sector than in the former, according to Blinder and Maccini (1991). Besides French data, we also analyze German and aggregate European data for the period 1985Q1-2011Q4. Indeed, it seems relevant to investigate separately French and German business cycles despite the launching of the European Monetary Union in 1999. First, our sample includes both pre and post euro periods. Then, despite a closer synchronization of EMU members business cycles in the recent period, there are still very different GDP patterns in euro area even among the core members. ${ }^{4}$

Our results suggest that both the linearity hypothesis and the null of no bounce-back in the threshold model are strongly rejected in the three cases. Moreover, the introduction of the bounce-back effect in the threshold model clearly improves the short-term forecasting performance for Germany and the European aggregate in the manufacturing sector and for France and the European aggregate in the retail trade sector. As regards the comparison of inventory investment behavior across sectors, it turns out that the bounce-back occurs later and lasts longer in manufacturing than in retail trade sector.

\footnotetext{
${ }^{2}$ See Kim et al. (2005) or Morley and Piger (2012) for an extension of the Markov-Switching model which allows bounce-back effects.

${ }^{3} \mathrm{PMI}$ survey also contains questions about the stocks of purchases and the stocks of finished goods in manufacturing industry and retail trade.

${ }^{4}$ The last recession episode provides a good illustration: German GDP fell sharply during the 2008-09 crisis (fall of almost 7\% in GDP between 2008Q1 and 2009Q1 in Germany as opposed to -4.3\% only in France) and symmetrically the recovery pace was much higher in Germany than in France $(+4.9 \%$ in the former versus $+1.6 \%$ in the latter).
} 
Finally, based on different data types and sources, countries and samples, our results confirm conclusions drawn in previous empirical works by Sichel (1994), Camacho et al. (2011) and Bec and Ben Salem (2013): The rebound in the real GDP growth rate at the end of recessions noticed by Friedman as early as in the sixties is also a feature of inventory investment behavior at business cycle frequencies. Since this feature is not found in final sales data, these results provide further evidence that the evolution of inventories rather than the evolution of sales seems to be behind the candidate explanations of the rapid recovery found in GDP growth. This in turn suggests that a careful modeling of inventory investment behavior must be a key ingredient in any sensible dynamic stochastic general equilibrium business cycle model.

The paper is organized as follows. Section 2 briefly presents the bounce-back augmented threshold autoregressive model and discusses the various shapes of bounce-back functions as special cases of the general model. Section 3 describes the data and presents the linearity tests before reporting the estimation results. Section 4 evaluates the short-run forecasting performances of the bounce-back models, paying careful attention to the last recession episode. Section 5 concludes.

\section{The bounce-back augmented threshold autoregressive model}

The model considered throughout this paper was first introduced by Bec et al. (2013). Denoting by $z_{t}$ the inventory investment series that we will discuss more precisely in the next section, the bounce-back augmented threshold autoregression is the following:

$$
\phi(L) z_{t}=\mu_{t}+e_{t}
$$

with $\mu_{t}$ defined by

$$
\begin{aligned}
\mu_{t}= & \gamma_{0}\left(1-s_{t}\right)+\gamma_{1} s_{t} \\
& +\lambda_{1} s_{t} \sum_{j=\ell+1}^{\ell+m} s_{t-j}+\lambda_{2}\left(1-s_{t}\right) \sum_{j=\ell+1}^{\ell+m} s_{t-j}+\lambda_{3} \sum_{j=\ell+1}^{\ell+m} \Delta y_{t-j-1} s_{t-j},
\end{aligned}
$$

and where $\phi(L)$ is a lag polynomial of order $p$ with roots lying outside the unit circle and $e_{t}$ i.i.d. $\mathcal{N}(0, \sigma)$. In the second equation, $\ell$ and $m$ are non-negative integers and correspond respectively to the delay with which the bounce-back effect occurs and to its duration. The $\lambda_{i}$ 's parameters measure the size of the bounce-back effect. The variable $s_{t}$ denotes the transition function which takes on the value zero or one. In our model, $s_{t}$ is defined as:

$$
s_{t}=0 \text { if } \Delta y_{t-1}>\kappa \text { and } 1 \text { otherwise, }
$$

where $\kappa$ is a real-valued threshold parameter and $\Delta y_{t-1}$ is the lagged growth rate of real GDP. ${ }^{5}$

The model given by equations (1) to (3) allows for an asymmetric behavior across regimes. Here, $s_{t}=1$ is identified as the low, or contraction regime by assuming $\kappa<0$. It implies

\footnotetext{
${ }^{5}$ Although this model, being autoregressive by nature, makes inventory investment depend on lagged variables only, it might also be seen as a reduced form representation compatible with a large set of theoretical decision rules, including forward-looking ones. See, e.g. Collard (1999), on this point.
} 
that the intercept in equation (1) is $\gamma_{0}$ if the lagged growth rate of real GDP, $\Delta y_{t-1}$, is larger than the threshold $\kappa$ (i.e. high, or expansion regime) and $\gamma_{1}$ otherwise. The remainder of equation (2) defines a very flexible form for the bounce-back phenomenon. If $\lambda_{1}$ is positive, then the term $\lambda_{1} s_{t} \sum_{j=\ell+1}^{\ell+m} s_{t-j}$ will increase $\mu_{t}$ above its low regime value $\left(\gamma_{1}\right), \ell+1$ quarters after the beginning of the recession and so until the recession comes to its end. Hence, this term activates during the recession only. If $\lambda_{2}$ is positive, then the value of $\mu_{t}$ will exceed $\gamma_{0}$ immediately after the recession is over. Finally, note that the third term of the bounce-back function depends on the depth of the last recession through the variable $\Delta y_{t-j-1}$ : negative values of $\lambda_{3}$ will drive $\mu_{t}$ above $\left(\gamma_{0}\left(1-s_{t}\right)+\gamma_{1} s_{t}\right)$ proportionally to the depth of the recession.

The $\mu_{t}$ function defined by equation (2) has the nice property that it nests the three models first proposed by Kim et al. (2005), namely the U-, V- and Depth-shaped bounceback $^{6}$ as well as the no bounce-back - standard threshold - model with the following linear restrictions:

- $\mathrm{H}_{0}^{N}: \lambda_{i}=0 \forall i$ corresponds to the standard (no bounce-back) threshold model,

- $\mathrm{H}_{0}^{U}: \lambda_{1}=\lambda_{2}=\lambda \neq 0$ and $\lambda_{3}=0$ gives the U-shaped model, hereafter denoted BBU,

- $\mathrm{H}_{0}^{V}: \lambda_{2} \neq 0$ and $\lambda_{1}=\lambda_{3}=0$ gives the BBV model,

- $\mathrm{H}_{0}^{D}: \lambda_{3} \neq 0$ and $\lambda_{1}=\lambda_{2}=0$ defines the BBD model.

The null hypothesis of linearity amounts here to test the joint hypothesis $\lambda_{1}=\lambda_{2}=\lambda_{3}=0$ and $\gamma_{0}=\gamma_{1}$, i.e. $\mu_{t}$ becomes a constant term. Obviously, the threshold parameter is unidentified under this null. Consequently, the linearity test will rely on a SupLR statistics along the lines proposed by Davies (1987) and its bootstrapped p-value will be computed following Hansen (1996). By contrast, since there are nuisance parameter free, the four assumptions $\mathrm{H}_{0}^{N}, \mathrm{H}_{0}^{U}, \mathrm{H}_{0}^{V}$ and $\mathrm{H}_{0}^{D}$ can be tested from a $\mathrm{LR}$ statistics which has a standard Chi-squared distribution.

Finally, the general model defined here by equations (1) to (3) will be denoted $\operatorname{BBF}(p, m, \ell)$, as in Bec et al. (2013). This BBF model is estimated along the lines described in Bec et al. (2013), from the nonlinear least squares method using a triple grid search on the $\ell, m$ and $\kappa$ parameters, for $\ell \in\{0,1,2\}, m \in\{0, \ldots, 8\}$ and $\kappa \in\left[\kappa_{l} ; \kappa_{u}\right]$ where $\kappa_{l}$ is the $5 \%$-quantile of the switching variable $\Delta y_{t}$ and $\kappa_{u}=0$ so as to define the low regime as a recession regime.

\section{Inventories investment nonlinear dynamics}

The data we consider throughout the analysis come from the European Commission total manufacturing industry and retail trade opinion survey, regarding the assessment of stocks. For industry it corresponds to Question 4 of the business opinion survey, namely:

"Do you consider your current stock of finished products to be...?

- + too large (above normal)

- = adequate (normal for the season)

\footnotetext{
${ }^{6}$ See Bec et al. (2011) and Bec et al. (2013) for a detailed description of these functions.
} 
- - too small (below normal)"

while for retail trade, it corresponds to Question 2 of the retail trade survey, namely: "Do you consider the volume of stock you currently hold to be...?", with the same three items as potential replies. The indicators are computed as the difference between positive (above normal) and negative (below normal) replies, expressed in percentage points and seasonally adjusted.

The data are available at the monthly frequency, but since the GDP are quarterly data, the survey balances are converted into quarterly frequency by averaging monthly observations. Our sample includes data for France, Germany and Europe over the period 1985Q1 to 2011Q4 but for the retail trade survey for Europe which starts in 1985Q4 only. To make these survey data comparable to contribution of inventories to GDP growth rate, we take their first difference. Actually, the use of series in first difference is more relevant since a lower destocking captured by a decrease in the survey variable from a high level contributes positively to the GDP growth rate and thus can take part to the rebound in real GDP growth. Contribution of inventories to GDP growth rate data are also considered in the empirical analysis by Sichel (1994) or Camacho et al. (2011) among others. Then, we use this series with inverted sign because a positive survey balance is most likely to correspond to a decrease in inventory investment. Indeed a positive balance means that a majority of business leaders consider their stock as too large, which implies at least that they stop increasing it further. ${ }^{7}$ The two countries and the European aggregate data are plotted in Figure 1, see Appendix.

Table I: Linearity tests results: Model I

\begin{tabular}{ccccccc}
\hline \hline Country & $p$ & $\hat{m}$ & $\hat{\ell}$ & $\hat{\kappa}$ & SupLR & p-value \\
\hline \multicolumn{6}{c}{ Manufacturing } \\
DE & 1 & 4 & 1 & -0.02 & 37.84 & 0.00 \\
FR & 1 & 3 & 2 & -0.11 & 15.41 & 0.01 \\
EA & 1 & 4 & 1 & -0.07 & 33.43 & 0.00 \\
& & \multicolumn{5}{c}{ Retail trade } \\
DE & 3 & 2 & 0 & -0.18 & 13.50 & 0.08 \\
FR & 3 & 2 & 0 & -0.11 & 9.75 & 0.09 \\
EA & 2 & 2 & 0 & -0.23 & 11.12 & 0.15 \\
\hline
\end{tabular}

Table I reports parameters $m, \ell$ and $\kappa$ estimates once the lag length parameter $p$ is fixed at the smallest value which eliminates estimated residuals serial correlation ${ }^{8}$. The columns SupLR and $p$-value report the results of the SupLR linearity test for 2,000 random draws under the null.

\footnotetext{
${ }^{7}$ Basically, our transformed survey data capture quite well the high-growth recovery following the end of recessions that is present in inventories contribution data from national accounts. For the sake of parsimony, we do not report the corresponding graphs but they are available upon request to the authors.

${ }^{8}$ Regarding the retail trade sector data, even though the BBF model residuals were found not serially correlated with zero lag in the German and French cases, it turns out that the third lag provides significant information regarding the dynamics of $\Delta x_{t}$ and hence, it is kept for the subsequent analysis.
} 
As can be seen from the bootstrapped $p$-values of the tests reported in the last column of Table I, the linearity null hypothesis is strongly rejected for the inventory investment in the total manufacturing industry. The evidence of nonlinearity is only slightly weaker in the retail trade sector. Regarding the bounce-back duration, it is longer for manufacturing (three to four quarters) than for retail trade (two quarters). It is also worth noticing that the effect activates earlier in the retail trade sector than in the manufacturing industry where it is delayed by one or two quarters. These findings are well in line with the widespread view that the adjustment of inventories to the desired level is quicker in retail trade than in manufacturing. As stressed by Blinder and Maccini (1991) from U.S. data, manufacturers' inventories of finished goods are the least volatile component of inventory investment.

Let us now test for the existence and more specific shapes of the bounce-back effect in Equation (2). The log-likelihood ratio test statistics corresponding to the various hypothesis are reported in Table II.

Table II: LR-Test for the shape of the bounce-back function

\begin{tabular}{ccccccc}
\hline \hline Country & $H_{1}: \mathrm{BBF}$ & $H_{0}^{N}:$ no BB & $H_{0}^{U}: \mathrm{BBU}$ & $H_{0}^{V}: \mathrm{BBV}$ & $H_{0}^{D}: \mathrm{BBD}$ & $H_{0}^{C}: \mathrm{BBF}_{c}$ \\
\hline \multicolumn{7}{c}{ Manufacturing } \\
DE & $(-202.77)$ & $\mathbf{3 3 . 5 0}$ & 1.40 & $\mathbf{1 1 . 7 4}$ & $\mathbf{2 1 . 1 8}$ & \\
FR & $(-259.81)$ & $\mathbf{1 3 . 1 8}$ & $\mathbf{9 . 1 8}$ & $\mathbf{1 1 . 4 8}$ & $\mathbf{1 5 . 9 4}$ & $2.20^{(a)}$ \\
EA & $(-172.71)$ & $\mathbf{2 9 . 9 2}$ & $\mathbf{1 5 . 0 8}$ & $\mathbf{2 6 . 3 0}$ & $\mathbf{2 7 . 1 6}$ & $3.18^{(a)}$ \\
& & \multicolumn{7}{c}{ Retail trade } \\
DE & $(-240.51)$ & $\mathbf{1 0 . 6 3}$ & $\mathbf{1 4 . 9 4}$ & $\mathbf{1 1 . 7 4}$ & $\mathbf{1 4 . 6 7}$ & $3.47^{(b)}$ \\
FR & $(-257.81)$ & $\mathbf{1 0 . 2 8}$ & $\mathbf{7 . 8 1}$ & $\mathbf{1 3 . 4 7}$ & $\mathbf{1 2 . 5 8}$ & $3.07^{(b)}$ \\
EA & $(-211.18)$ & $\mathbf{1 0 . 8 7}$ & $\mathbf{6 . 4 9}$ & $\mathbf{1 0 . 7 7}$ & $\mathbf{7 . 4 7}$ & $1.91^{(b)}$ \\
\hline
\end{tabular}

Notes: Figures into parenthesis are log-likelihoods.

Bold characters denote rejection of the null at the 5\%-level.

Superscripts $(a)$ and $(b)$ correspond to the constraints $\lambda_{3}=0$ and $\lambda_{2}=\lambda_{3}=0$ respectively.

Regarding the manufacturing sector, the null of no bounce-back effect is always strongly rejected. In the German case, the U-shaped bounce-back model is not rejected since the $p$-value of the $\chi^{2}(2)$ distributed LR statistics is 50\%. In France and Europe, the standard U-, V-, and Depth-shaped bounce-back functions are strongly rejected ${ }^{9}$. A closer look at the BBF model estimates ${ }^{10}$ reveals that $\lambda_{3}$ is not significantly different from zero, which is confirmed by the LR statistics reported in the last column of Table II. This constrained BBF model will hence be kept for the subsequent analysis. In the retail trade sector, the null of no bounce-back is again strongly rejected. So are the existing U, V and D-shaped bounce-back patterns. When looking at the BBF model estimates ${ }^{11}$, it turns out that only

\footnotetext{
${ }^{9}$ This finding is consistent with Camacho et al. (2011)'s conclusion that the rebound is not V-shaped anymore since the Great Moderation in the US. However, the constrained BBF models retained here are less pessimistic than the L-shaped model these authors point to: although slighter than in a V-shaped model, our constrained BBF models still predict a rebound.

${ }^{10}$ Not reported but available upon request.

${ }^{11}$ Not reported but available upon request.
} 
Table III: Models estimates

\begin{tabular}{|c|c|c|c|c|c|c|}
\hline & $\overline{\mathrm{DE}}$ & $\overline{F R}$ & $\mathrm{EA}$ & $\overline{\mathrm{DE}}$ & FR & EA \\
\hline & \multicolumn{3}{|c|}{ Manufacturing } & \multicolumn{3}{|c|}{ Retail trade } \\
\hline \multirow[t]{2}{*}{$\gamma_{0}$} & -1.03 & -0.66 & -0.20 & 0.27 & -0.16 & 0.03 \\
\hline & $(0.32)$ & $(0.42)$ & $(0.17)$ & $(0.35)$ & $(0.33)$ & $(0.21)$ \\
\hline \multirow{2}{*}{$\gamma_{1}$} & -2.56 & -0.13 & -1.80 & -2.19 & -1.37 & -2.24 \\
\hline & $(0.50)$ & $(1.45)$ & $(0.60)$ & $(0.86)$ & $(1.41)$ & (1.11) \\
\hline \multirow[t]{2}{*}{$\lambda_{1}$} & 1.22 & 5.23 & 1.98 & 2.61 & 3.58 & 2.38 \\
\hline & $(0.20)$ & $(2.57)$ & $(0.44)$ & (1.07) & $(1.32)$ & $(0.79)$ \\
\hline \multirow[t]{2}{*}{$\lambda_{2}$} & 1.22 & 1.57 & 0.55 & & & \\
\hline & & $(0.61)$ & $(0.19)$ & & & \\
\hline$\lambda_{3}$ & 0.00 & 0.00 & 0.00 & & & \\
\hline \multirow[t]{2}{*}{$\phi_{1}$} & 0.53 & 0.27 & 0.60 & 0.04 & -0.23 & -0.03 \\
\hline & $(0.07)$ & $(0.10)$ & $(0.07)$ & $(0.09)$ & $(0.10)$ & $(0.10)$ \\
\hline \multirow[t]{2}{*}{$\phi_{2}$} & & & & 0.04 & -0.12 & -0.17 \\
\hline & & & & $(0.10)$ & $(0.10)$ & $(0.09)$ \\
\hline \multirow[t]{2}{*}{$\phi_{3}$} & & & & -0.17 & -0.15 & \\
\hline & & & & $(0.09)$ & $(0.09)$ & \\
\hline$\sigma$ & 2.01 & 3.72 & 1.51 & 3.20 & 3.23 & 2.06 \\
\hline$n_{0}$ & 76 & 97 & 96 & 85 & 97 & 95 \\
\hline$n_{1}$ & 31 & 10 & 11 & 22 & 10 & 9 \\
\hline $\mathrm{R}^{2}$ & 0.63 & 0.21 & 0.60 & 0.11 & 0.13 & 0.12 \\
\hline $\mathrm{Q}(4)[\mathrm{p}$-val $]$ & {$[0.25]$} & {$[0.67]$} & {$[0.39]$} & {$[0.99]$} & {$[0.99]$} & {$[0.59]$} \\
\hline
\end{tabular}

Notes: Figures into parenthesis are standard deviations.

Characters in italic denote constrained values.

$n_{i}$ is the number of obs. in regime $i$.

$\lambda_{1}$ is significantly different from zero. The test of the joint hypothesis $\lambda_{2}=\lambda_{3}=0$ reported in the last column of Table II - never rejects the null. Finally, in Table III, we report the constrained BBF versions but for German manufacturing data where the BBU model is retained.

$\lambda_{1}$ and $\lambda_{2}$ ' estimates have the expected sign in the six models, i.e. they are positive which corresponds to a larger value for $\mu_{t}$. A quick glance at the estimated bounce-back effects, i.e. $\hat{\mu}_{t}-\hat{\gamma}_{0}\left(1-s_{t}\right)-\hat{\gamma}_{1} s_{t}$, see Figure 2 reported in appendix, reveals that it activates more often and lasts longer in the manufacturing sector (graphs on the left-hand side) than in the retail trade (right-hand side). The bounce-back magnitude is comparable in both sectors during the last recession, but it is triggered earlier in the recession in the retail trade sector than in manufacturing. Since $\lambda_{2}=\lambda_{3}=0$ for retail trade data, the bounce-back effect stops as soon as the recession is over. During the 1992 and 2002 recessions, the estimated bounce-back effects are twice as large in the manufacturing sector as in the retail trade sector. In the later, the recession which occurred in the early 2000s did not generate any bounce-back effect according to French and European models estimates. 


\section{Forecasting accuracy evaluation}

As an additional check of the added value of the BBF models over the linear specification, the one-step ahead forecasts are calculated from a pseudo-real time analysis using recursive regressions performed from $\mathrm{T}_{0}=2006 \mathrm{Q} 1$ to $\mathrm{T}_{f}=2011 \mathrm{Q} 4$.

For all $t \in\left\{T_{0}, \ldots, T_{f}-1\right\}$, we estimate the model from the first available observation until $t$, and use this estimate to compute the one-step-ahead forecasts. Then, we decompose the last crisis episode into the recession time and the recovery, beginning the quarter just after the trough. ${ }^{12}$ These forecasts are compared with those obtained from a benchmark linear autoregression, i.e. imposing a constant value for $\mu_{t}$ in equation (1). The added value of the bounce-back term is also assessed by comparing these forecasts to a standard SETAR model.

Table IV: 1-step ahead forecasts (relative RMSE criterion): Manufacturing

\begin{tabular}{lcccc}
\hline \hline Model & Evaluation & Recession and recovery & Recession & Recovery \\
\hline \multicolumn{5}{c}{ GERMANY } \\
dates & 2006q1-2011q4 & 2008q3-2011q4 & 2008q3-2009q1 & 2009q2-2011q4 \\
AR $(1)^{*}$ & 3.40 & 4.27 & 5.71 & 3.78 \\
$\operatorname{TAR}(1)$ & 0.98 & 0.97 & 0.93 & 1.01 \\
$\operatorname{BBF}(1,4,1)$ & 0.82 & 0.80 & 0.80 & 0.81 \\
$\operatorname{BBU}(1,4,1)$ & $\mathbf{0 . 7 9}$ & $\mathbf{0 . 7 7}$ & $\mathbf{0 . 7 8}$ & $\mathbf{0 . 7 7}$
\end{tabular}

FRANCE

$\begin{array}{lcccc}\text { dates } & 2006 \mathrm{q} 1-2011 \mathrm{q} 4 & 2008 \mathrm{q} 2-2011 \mathrm{q} 4 & 2008 \mathrm{q} 2-2009 \mathrm{q} 1 & 2009 \mathrm{q} 2-2011 \mathrm{q} 4 \\ \operatorname{AR}(1)^{*} & 4.24 & 5.07 & \mathbf{4 . 3 3} & 5.31 \\ \operatorname{TAR}(1) & 1.00 & 1.00 & 1.10 & 0.97 \\ \operatorname{BBF}(1,3,2) & 1.13 & 1.14 & 1.06 & 1.16 \\ \operatorname{BBF}_{c}(1,3,2) & \mathbf{0 . 9 9} & \mathbf{0 . 9 9} & 1.06 & \mathbf{0 . 9 7}\end{array}$

\begin{tabular}{lcccc}
\multicolumn{5}{c}{ European AGGREGATE } \\
dates & $2006 \mathrm{q} 1-2011 \mathrm{q} 4$ & $2008 \mathrm{q} 2-2011 \mathrm{q} 4$ & $2008 \mathrm{q} 2-2009 \mathrm{q} 2$ & $2009 \mathrm{q} 3-2011 \mathrm{q} 4$ \\
$\operatorname{AR}(1)^{*}$ & 2.20 & 2.74 & 3.55 & 2.24 \\
$\operatorname{TAR}(1)$ & 1.06 & 1.07 & 1.06 & 1.07 \\
$\operatorname{BBF}(1,4,1)$ & 0.86 & 0.85 & $\mathbf{0 . 7 4}$ & 0.97 \\
$\operatorname{BBF}_{c}(1,4,1)$ & $\mathbf{0 . 8 4}$ & $\mathbf{0 . 8 2}$ & 0.75 & $\mathbf{0 . 9 1}$ \\
\hline
\end{tabular}

*: All RMSE, but the ones of the AR models, are given relative to the AR model RMSE.

We report the RMSE relative to the AR benchmark (a ratio below 1 indicates a gain relative to AR) in Tables IV and $\mathrm{V}$ for the manufacturing and retail trade sectors respectively. In manufacturing, the BBF models almost always outperform the linear model or the TAR model without bounce-back effect (RMSE ratio far below one on the whole evaluation period and on each sub-period), but the results are less clear cut in the French case: the best ratio

\footnotetext{
${ }^{12}$ The recession dates come from the ECRI for Germany and France and were calculated following the Bry and Boschan (1971) algorithm adapted to quarterly data for the European aggregate.
} 
Table V: 1-step ahead forecasts (relative RMSE criterion): Retail trade

\begin{tabular}{lcccc}
\hline \hline Model & Evaluation & Recession and recovery & Recession & Recovery \\
\hline & \multicolumn{5}{c}{ GERMANY } \\
dates & 2006q1-2011q4 & 2008q3-2011q4 & 2008q3-2009q1 & 2009q2-2011q4 \\
$\operatorname{AR}(3)^{*}$ & $\mathbf{3 . 9 7}$ & $\mathbf{4 . 4 1}$ & $\mathbf{6 . 2 8}$ & 3.74 \\
$\operatorname{TAR}(3)$ & 1.03 & 1.04 & 1.04 & 1.05 \\
$\operatorname{BBF}(3,2,0)$ & 1.01 & 1.00 & 1.07 & $\mathbf{0 . 9 4}$ \\
$\operatorname{BBF}_{c}(3,2,0)$ & 1.01 & 1.00 & 1.06 & 0.96
\end{tabular}

\begin{tabular}{lcccc}
\multicolumn{5}{c}{ FRANCE } \\
dates & $2006 \mathrm{q} 1-2011 \mathrm{q} 4$ & $2008 \mathrm{q} 2-2011 \mathrm{q} 4$ & $2008 \mathrm{q} 2-2009 \mathrm{q} 1$ & $2009 \mathrm{q} 2-2011 \mathrm{q} 4$ \\
$\mathrm{AR}(3)^{*}$ & 2.66 & 3.31 & 2.68 & 3.51 \\
$\operatorname{TAR}(3)$ & 0.97 & 0.96 & 0.94 & 0.96 \\
$\operatorname{BBF}(3,2,0)$ & 0.94 & 0.93 & $\mathbf{0 . 4 7}$ & 1.00 \\
$\operatorname{BBF}_{c}(3,2,0)$ & $\mathbf{0 . 8 3}$ & $\mathbf{0 . 8 2}$ & 0.67 & $\mathbf{0 . 8 5}$
\end{tabular}

\begin{tabular}{lcccc} 
& \multicolumn{5}{c}{ European AGgREGATE } \\
dates & 2006q1-2011q4 & 2008q2-2011q4 & $2008 \mathrm{q} 2-2009 \mathrm{q} 2$ & $2009 \mathrm{q} 3-2011 \mathrm{q} 4$ \\
$\operatorname{AR}(2)^{*}$ & 1.73 & 1.97 & 1.93 & 2.08 \\
$\operatorname{TAR}(2)$ & 1.02 & 1.04 & 1.01 & 1.09 \\
$\operatorname{BBF}(2,2,0)$ & $\mathbf{0 . 8 4}$ & $\mathbf{0 . 8 0}$ & $\mathbf{0 . 7 7}$ & 0.87 \\
$\operatorname{BBF}_{c}(2,2,0)$ & 0.87 & 0.84 & 0.87 & $\mathbf{0 . 7 8}$ \\
\hline
\end{tabular}

*: All RMSE, but the ones of the AR models, are given relative to the AR model RMSE.

reaches only 0.97 during the last recovery. In retail trade, the results are quite disappointing in Germany where the only sub-period favorable to the bounce-back model is the last recovery but are strongly favorable to the BBF model in France and in Euro Area again.

\section{Conclusion}

This paper explores the existence of a bounce-back effect in inventory investment using the European Commission opinion survey on stocks of finished products in manufacturing and retail trade. The data are quarterly balance (in percentage points) of positive over negative results for France, Germany and a European aggregate, from 1985q1 to 2011q4. Using the bounce-back augmented threshold autoregression first proposed by Bec et al. (2011), our empirical findings support the existence of a high recovery episode for contribution of inventory investment to GDP growth, during the quarters immediately following the recessions. As expected, this bounce-back episode occurs later and lasts longer in manufacturing than in retail trade sector.

Since a third phase of rapid recovery has not been found in final sales data so far, the inventory investment bounce-back found here could explain the real GDP growth rate bounce-back pointed out in previous empirical studies. In order to check this, the extension of the analysis to the joint dynamics of real GDP growth rate and inventory investment opinion survey data is on our research agenda. If further confirmed, these results point to 
the need for a very careful modeling of the inventory investment behavior in any sensible theoretical explanation of aggregate business cycles.

\section{References}

Abramovitz, M. (1950) Inventories and Business Cycles, New York: National Bureau of Economic Research.

Bec, F. and M. Ben Salem (2013) "Inventory Investment and the Business Cycle: The Usual Suspect", Studies in Nonlinear Dynamics and Econometrics 3, 335-343.

Bec, F., O. Bouabdallah and L. Ferrara (2011) "The possible shapes of recoveries in Markov switching models" CREST Working Paper 2011-02.

Bec, F., O. Bouabdallah and L. Ferrara (2013) "The European Way Out of Recessions" forthcoming in International Journal of Forecasting.

Blinder, A.S. (1981) "Retail Inventory Behavior and Business Fluctuations" Brookings Papers on Economic Activity 2, 443-505.

Blinder, A.S. (1986) "Can the Production Smoothing Model of Inventory Behavior Be Saved" Quarterly Journal of Economics 101(3), 431-453.

Blinder, A.S. and L.J. Maccini (1991) "Taking Stock: A Critical Assessment of Recent Research on Inventories" Journal of Economic Perspectives, 5(1), 73-96.

Bry, G. and C. Boschan (1971) Cyclical Analysis of Time Series: Selected Procedures and Computer Programs, New York and London: Columbia University Press.

Camacho, M., G. Perez Quiros and H. Mendizabal (2011) "High-growth recoveries, inventories and the Great Moderation" Journal of Economic Dynamics and Control 35, 13221339.

Collard, F. (1999) "Spectral and persistence properties of cyclical growth" Journal of Economic Dynamics and Control 23, 463-488.

Davies, R. B. (1987) "Hypothesis Testing When a Nuisance Parameter is Present Only Under the Alternative" Biometrika 74, 33-43.

de Rougemont, P. (2011) "Les stocks dans la crise" Bulletin de la Banque de France 183.

Eichenbaum, M. (1989) "Some Empirical Evidence on the Production Level and Production Cost Smoothing Models of Inventories" American Economic Review 79(4), 853-864.

Friedman, M. (1993) "The plucking model of business fluctuations revisited" Economic Inquiry 31(2), 171-177.

Hansen, B.E. (1996) "Inference when a Nuisance Parameter Is Not Identified Under the Null Hypothesis" Econometrica 64(2), 413-430.

Kahn, J. (1987) "Inventories and the Volatility of Production" The American Economic Review 77(4), 667-679.

Kim, C.-J. and C. Nelson (1999) "Friedmans plucking model of business fluctuations: Tests and estimates of permanent and transitory components" Journal of Money, Credit, and Banking 31, 317-334.

Kim, C.-J., J. Morley and J. Piger (2005) "Nonlinearity and the permanent effects of recessions" Journal of Applied Econometrics 20, 291-309.

Morley, J. and J. Piger (2012) "The asymmetric business cycle" Review of Economics and Statistics 94, 208-221. 
Sichel, E. (1994) "Inventories and the Three Phases of the Business Cycles" Journal of Business and Economic Statistics 12(3), 269-277.

Wang, P. and Y. Wen (2009) "Inventory Accelerator in General Equilibrium" Federal Reserve Bank of St. Louis working paper 010.

Wang, P., Y. Wen and Z. Xu (2011) "When Do Inventories Destabilize the Economy? An Analytical Approach to (S,s) Policies" Fed. Reserve Bank of St. Louis working paper 014 . 


\section{Appendix}
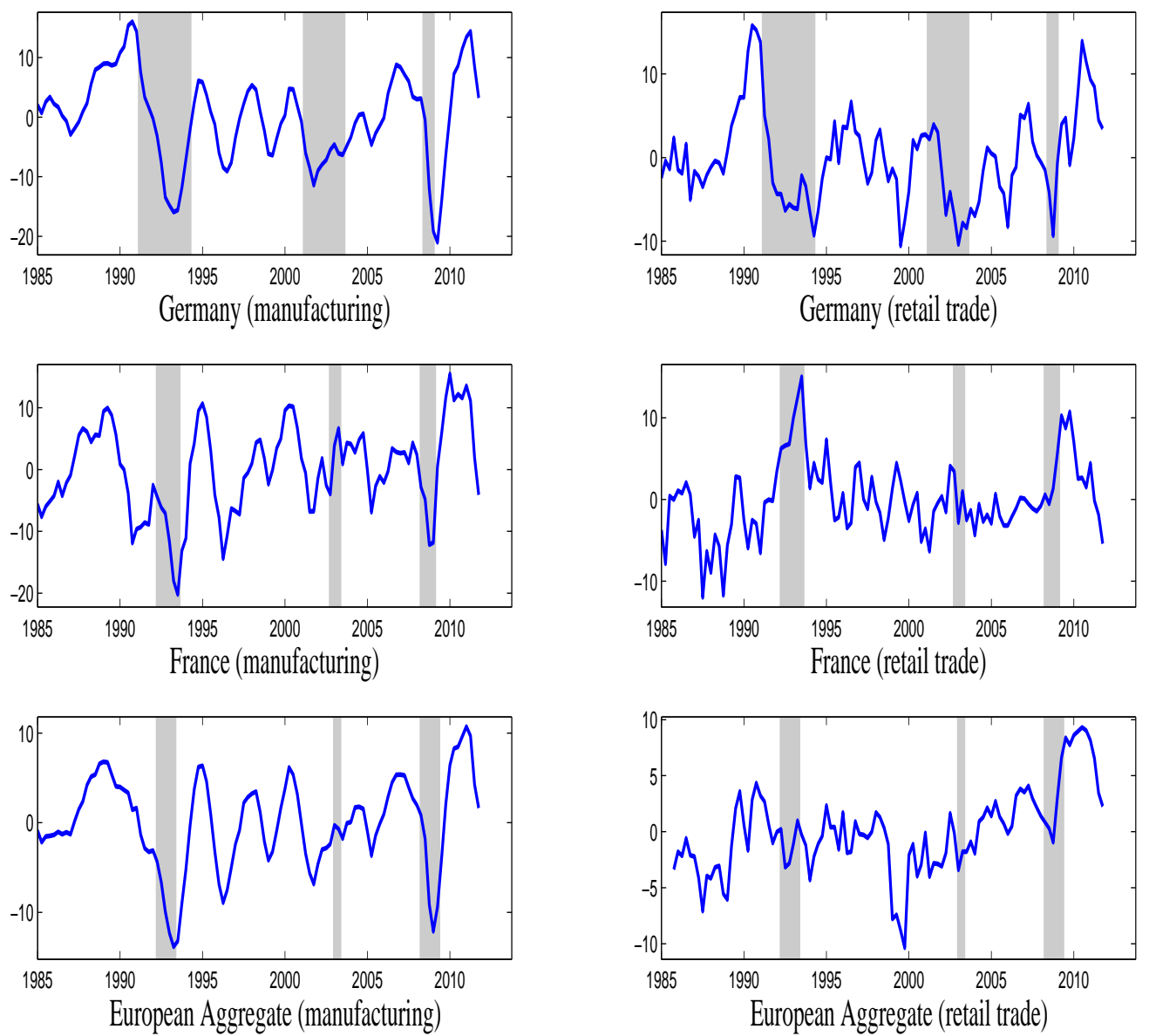

Figure 1: Centered balance of positive over negative opinions (inverted sign) 

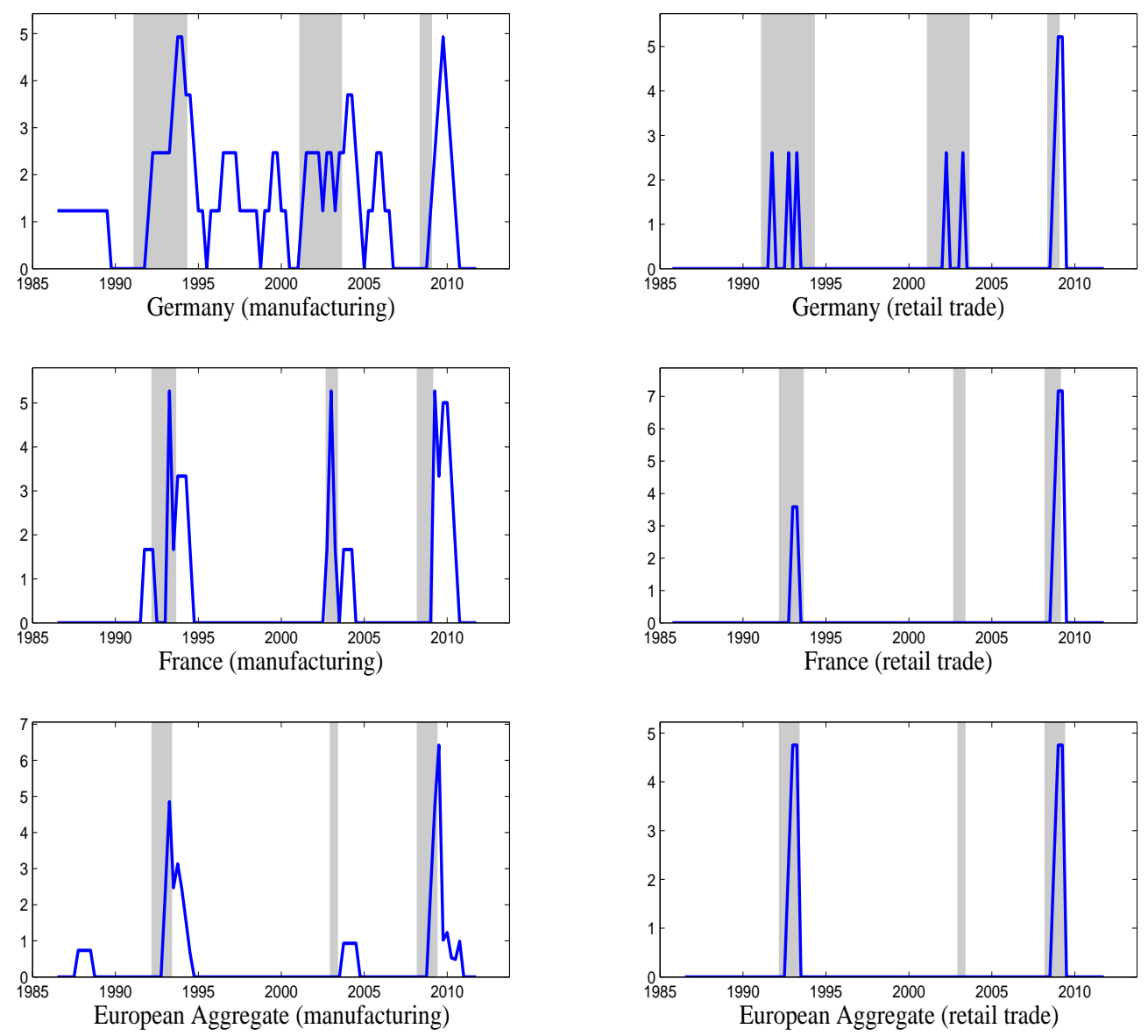

Figure 2: Estimated bounce-back functions 